\title{
Evaluation of aquifer potential, geoelectric and hydraulic parameters in Ezza North, southeastern Nigeria, using geoelectric sounding
}

\author{
D. N. Obiora ${ }^{1} \cdot$ J. C. Ibuot $^{1} \cdot$ N. J. George ${ }^{2}$
}

Received: 19 April 2015/Revised: 13 August 2015/Accepted: 2 September 2015/Published online: 14 September 2015

(C) Islamic Azad University (IAU) 2015

\begin{abstract}
A geoelectric survey involving vertical electrical sounding (VES) employing Schlumberger electrode configuration was carried out with the aim of evaluating the aquifer potential, electric and hydraulic parameters in Ezza North. Schlumberger electrode configuration was used to acquire data for twelve VES stations. The interpreted and analyzed results reveal four to six geoelectric layers. The VES curves obtained were QQH, QHK, QHA, QQQ, HAK, KHK, HKH and QQ. From the result, the Dar Zarrouk parameters (longitudinal conductance and transverse resistance) were calculated. The longitudinal conductance ranges between 0.1528 and 4.6 mhos. The transverse resistance ranges between 662.4 and $38,808 \Omega \mathrm{m}^{2}$. The range of hydraulic conductivity is $1.1645-38.0491 \mathrm{~m} /$ day, while the range of transmissivity is $89.66-2100.3 \mathrm{~m}^{2} /$ day from the estimated values. The contour maps were drawn using the electrical and hydraulic parameters, and the distribution of the aquifer parameters is shown. Based on the results, aquifer potential and protective capacity of the study area were determined.
\end{abstract}

Keywords Aquifer potential - Ezza North · Hydraulic conductivity · Longitudinal conductance · Transmissivity · Transverse resistance

D. N. Obiora

daniel.obiora@unn.edu.ng

1 Department of Physics and Astronomy, University of Nigeria, Nsukka, Enugu State, Nigeria

2 Department of Physics, Akwa Ibom State University, Ikot Akpaden, Uyo, Akwa Ibom State, Nigeria

\section{Introduction}

A detailed knowledge of the subsurface geology and structure is provided by the geophysical surveys. Electrical resistivity method has been used successfully in delineation and exploitation of groundwater (Evans et al. 2010; George et al. 2010; Ibuot et al. 2013). It gives detailed information about hydrogeological settings and groundwater repositories. Groundwater is that water contained in the voids of the geologic materials that comprise the crust of the earth and exists at a pressure greater than or equal to atmospheric pressure (Al Sabahi et al. 2009). Comparatively, groundwater is less exposed to contamination than surface water. This reason underscores the reason, while it is more preferable to surface water. To man, groundwater has provided a great socioeconomic benefits including domestic and industrial uses, irrigation and tourism. In groundwater exploration, vertical electrical sounding (VES) employing Schlumberger electrode configuration is a common geophysical technique (Ezeh and Ugwu 2010; Olawuyi and Abolarin 2013; George et al. 2011; Ibuot et al. 2013). This is because instrumentation is simple; field logistics are easy and straightforward, while the analysis of data is less tedious and economical (Zohdy et al. 1974; Ekine and Osobonye 1996). The resistivity method is aimed at measuring the potential differences on the surface due to the current flow within the ground. Since the mechanisms that control the fluid flow and electric current and conduction are generally governed by the same physical parameters and lithological attributes, the hydraulic and electrical conductivities are dependent on each other (George et al. 2015).

The need for water in the study area has aroused interest in the use of groundwater due to lack of surface water both saline and fraught with coliform. Most of the hand-dug 
wells or drilled boreholes have been done without any preliminary geophysical investigations. This has resulted to failures of some boreholes and contamination of water which has resulted to various waterborne diseases. None of the surface water is as hygienic or as economical for exploitation as the groundwater (Singh 2007). Groundwater is recommended for its natural microbiological quality and its general chemical quality for most uses (McDonald et al. 2002). The guinea worm infestations in some parts of Ebonyi State are attributed to ignorance and lack of safe drinking water (Okoronkwo 2003). The people of Ezza lack functional boreholes and depend only on ponds and other existing contaminated and coliform-stricken surface sources which are open to physical, chemical and microbial contaminations. The inhabitants of the area had suffered severely from the outbreak of guinea worm, and they trek long distances in search of water, especially during dry season. The area has argillaceous minerals that seem to act as a protective cover to the underlying layers. The intrusions that gave rise to the existence of rocks and minerals during the Santonian uplift account for several fractures within the shale. These fractures contain water, serving as aquifer. Groundwater flow in fractured aquifers is very complicated, and accuracy in estimation of the hydraulic parameters depends on the hydraulic behavior in particular fractures, which is site specific (Singh 2005).

The determination of aquifer characteristics involves the analysis and interpretation of soil and water samples of drilled boreholes, but due to the fact that these tests are capital and labor intensive, a noninvasive geoelectrical method (vertical electrical sounding) is used as an alternative to pumping tests. This paper attempts to evaluate aquifer potential, geoelectric and hydraulic parameters in the study area.

\section{Location and geology of the study area}

The study area lies between latitudes $06^{\circ} 09^{\prime} \mathrm{N}$ and $06^{\circ} 18^{\prime} \mathrm{N}$ of the equator and longitudes $07^{\circ} 54^{\prime} \mathrm{E}$ and $08^{\circ} 02^{\prime} \mathrm{E}$ of the Greenwich Meridian (Fig. 1). The area covers about 246 square kilometers and lies in the southeastern part of Nigeria. The study area belongs to the Asu River group shales. The sediments of the Asu River group which was formed during the Albian times were folded into open northeast trend known as Abakaliki Anticlinorium (Reyment 1965). The Asu River group is overlain by succession of shales, siltstones and sandstones, with shallow marine fauna, and is estimated to have a maximum thickness of about $200 \mathrm{~m}$. There are some mineral intrusions which may have contributed to its numerous fractures. The geological survey around the area reveals that the location is part of the Ebonyi Formation that overlies the Abakaliki siltstone and sandstone previously referred to in the literature as Unknown "Formation" (Reyment 1965). It is now referred to as Ebonyi Formation (Agumanu 1989). The Formation underlies a gentle undulating terrain in Ntezi-Ezamgbo area and southward to Amagu-Agba in Ebonyi State. The Ebonyi River and its tributaries (Akaduru, Nramura and Isumutu Rivers) form the major drainage system in the area. The formation is divided into three units from top to bottom. The upper siltstone-shale sequence is exposed at Amagu-Agba village. It consists essentially of rapidly alternating siltstone and silty shale with occasional thin sandstone beds. The middle limestone-siltstone sequence unit outcrops at a quarry, $2 \mathrm{~km}$ from Ekemoha to Agba road junction. It consists of minor sandstone, siltstone, limestone and shale. Lastly, the lower mudstone-shale sequence exposed at Umuezeoke, along drainage cut by River Akaduru. This sequence is grayish, occasionally flesh-colored and bedded with dark micaceous steaks. The study area has elevation between 57 and $89 \mathrm{~m}$ above sea level. Marshy conditions of lower elevation that also exist within the area are noted for rice production in the area. Most of the streams existing in the area are seasonal. The seasonal rivers which are active during the rainy seasons have the major drainage, the Ebonyi River, which flows to the Cross River, some distance to the south near Afikpo. The mudstones are highly weathered on the top. Significant groundwater is only found where the mudstone and shale are highly fractured.

\section{Materials and methods}

Twelve (12) vertical electrical soundings (VES) were carried out in the study area using OHMEGA SAS1000 Terrameter with its accessories. The Schlumberger electrode array was employed for each VES profile with half current $\left(\frac{A B}{2}\right)$ electrode separation of $150 \mathrm{~m}$ and half potential $\left(\frac{M N}{2}\right)$ electrode separation of $15 \mathrm{~m}$. To reduce the field data to their equivalent geological models, both manual and computer modeling techniques were employed (Zohdy et al. 1974; Akpan et al. 2009). The observed field data were converted to apparent resistivity $\left(\rho_{a}\right)$ values using Eq. (1):

$\rho_{a}=\pi \cdot\left[\frac{\left(\frac{A B}{2}\right)^{2}-\left(\frac{M N}{2}\right)^{2}}{M N}\right] \cdot R_{a}$

The manual procedure was done by plotting a graph of apparent resistivity against half-electrode spacing using a bi-logarithmic graph, and the curves generated were smoothened to remove the effects of lateral inhomogeneities and other forms of noisy signatures (Bhattacharya and Patra 1968; Chakravarthi et al. 2007). 


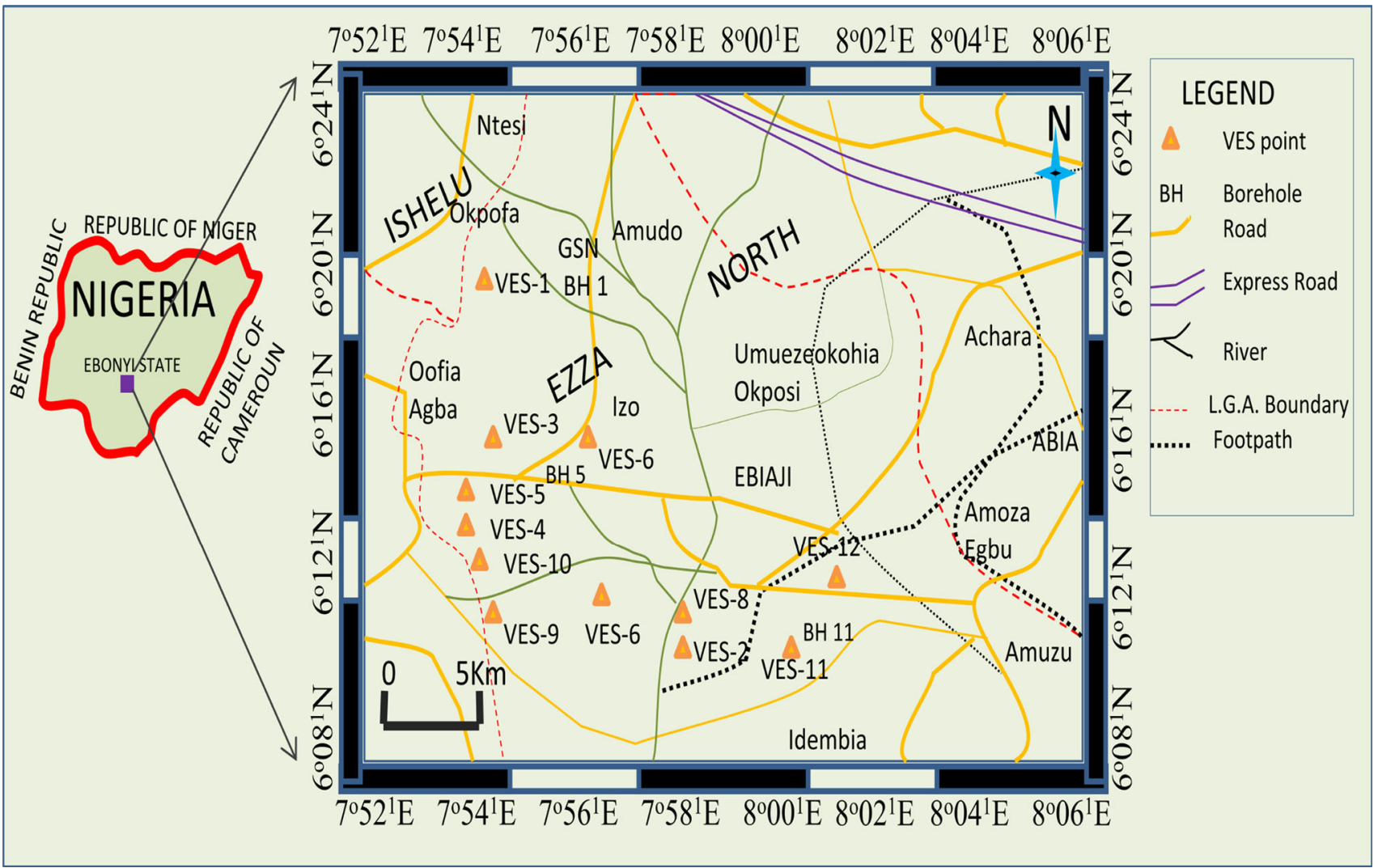

Fig. 1 Location map of the study area showing VES points

A conventional manual curve procedure using master curves and auxiliary charts (Orellana and Mooney 1966) was used to quantitatively interpret the smoothened curves in terms of true resistivity and thickness. The parameters obtained from curve matching were used by the computer software RESOUND as input data for the computer iterative modeling. Figure 2 shows typical geologic models obtained along with their correlations with nearby boreholes. For the interpretation and understanding of the geologic model, some parameters related to different combination of thickness and resistivity of geoelectrical layer are necessary (Zohdy et al. 1974; Maillet 1947). These are the Dar Zarrouk parameters: longitudinal conductance $(S)$ and transverse resistance $(T)$, which are, respectively, given by:

$S=\frac{h}{\rho}$

$T=h \rho$

where $h$ is the layer thickness in meters and $\rho$ is the electrical resistivity of the layer in ohmmeters. Since the area has the same characteristics as the one studied by (Heigold et al. 1979), the hydraulic conductivity $(K)$ was estimated using
$K=386.40 R_{\mathrm{rw}}^{-.93283}$

where $R_{\mathrm{rw}}$ is the resistivity of the aquifer. The aquifer transmissivity $\left(T_{\mathrm{r}}\right)$ was estimated using the relation (Niwas and Singhal 1981):

$T_{\mathrm{r}}=K \sigma T=\frac{K S}{\sigma}=K h$

where $\sigma$ is the electrical conductivity (inverse of resistivity), $S$ is the longitudinal conductance and $T$ is the transverse resistance. Equations (4) and (5) were used in this study to determine the hydraulic conductivity and transmissivity of aquifers, which depends on lithology and salinity of an area.

The reflection coefficient ( $\mathrm{Rc}$ ) and fractured contrast (Fc) shown in Table 2 were calculated using Eqs. 6 and 7, respectively;

$\mathrm{Rc}=\frac{\rho_{n}-\rho_{n-1}}{\rho_{n}+\rho_{n-1}}$

$\mathrm{Fc}=\frac{\rho_{n}}{\rho_{n-1}}$

where $\rho_{n}$ is the resistivity of the nth layer and $\rho_{n-1}$ is the layer resistivity overlying the $n$th layer. 

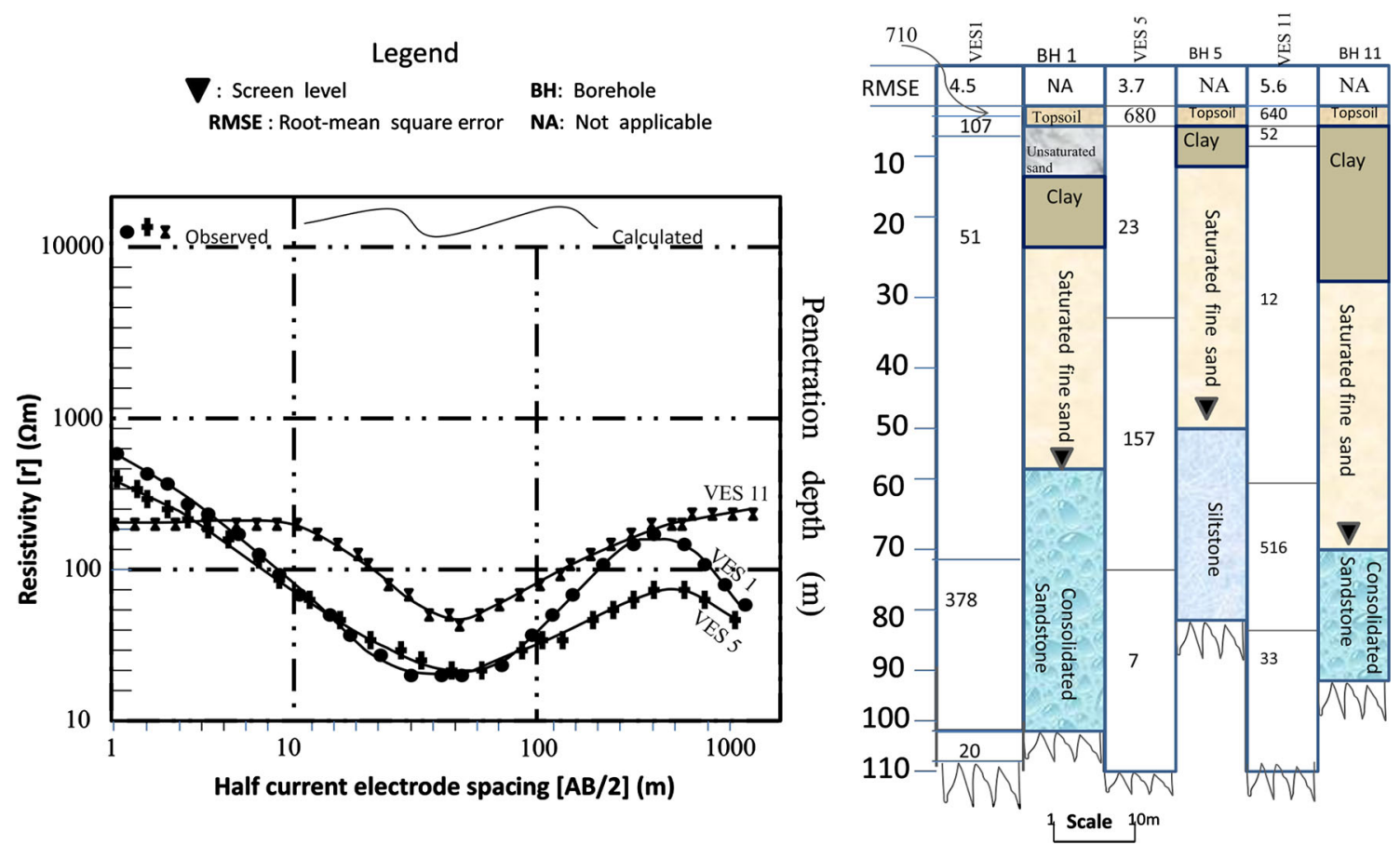

Fig. 2 Samples of 1-D derived modeled VES curves correlating with nearby borehole

\section{Results and discussion}

The results of the geoelectric sounding data revealed four to six geoelectric layers with varying intrafacies and interfacies changes (Table 1). The third and fourth layers constitute the aquiferous zones except VES 9 (OhaccaraNdiegu-Ohaccara) where the aquifer is the fifth layer. Eight geoelectric curve types were identified and grouped as: QQH $(25 \%), 16.7 \%$ of QHK and QHA, while $8.3 \%$ represents QQQ, HAK, KHK, HKH and QQ.

The first layer resistivity and thickness range between 90-5800 $\Omega \mathrm{m}$ and 1.0-1.7 m, respectively, and consists of the top lateritic sand. The second layer has resistivity and thickness range of $30-1740 \Omega \mathrm{m}$ and $0.2-8.5 \mathrm{~m}$, respectively. The third layer has a resistivity range of $3.0-285 \Omega \mathrm{m}$ and thickness range of $25-214.7 \mathrm{~m}$ with that of VES 10 (Ndiegu-Ekka-Onunwode Ndiegu) undefined. This layer harbors most of the aquifers in the study area. The fifth layer with resistivity range of $3-576 \Omega \mathrm{m}$ has infinite thickness in most of the study area.

Resistivity of the aquifer layers is shown in Table 2 with an average value of $95.42 \Omega \mathrm{m}$. The variability of its resistivity values is shown in Fig. 3. It reveals that the greater part of the study area is characterized by low aquifer resistivity values $<500 \Omega \mathrm{m}$. Areas with resistivity values $<100 \Omega \mathrm{m}$ indicate argillaceous formation facies which may lower the aquifer potentials, but areas with resistivity values $>100 \Omega \mathrm{m}$ (Ogboji-Eguo-Ugwu and Ohaccara-Ndiagu-ohaccara) indicate clay-sand sequence, and this is an indication of good aquifer formation. Figure 3 shows that high resistivity is obtainable in the southeastern part of the study area.

Figure 4 is an isopach contour map showing the variation in aquifer thickness in the study area. The values of aquifer thickness range from 34.1 to $214.7 \mathrm{~m}$ at AdiaguOguji Nwudor and Ndiegu-Ogboji-Ukwu Akpara, respectively, with an average value of $71.95 \mathrm{~m}$. The map shows the increase in aquifer thickness from the eastern part to the western part of the study area.

The distribution of aquifer longitudinal conductance $(S)$ is shown in Fig. 5. The values range from 0.1528 at Ogboji-Egwu-Ugwu to 4.6 mhos at Ekka integrated primary school, Ekka, with an average value of 1.6219 mhos. From Table 2, the longitudinal conductance values aided in classification of the study area into weak, moderate and good aquifer protective capacity. VES 8 (Ogboji-Eguo-Ugwu) was classified as weak. VES 1, 7 and 9 were classified as moderate, while the rest have good aquifer protective capacity, according to Henriet (1976) classification. VES 8 is vulnerable to 


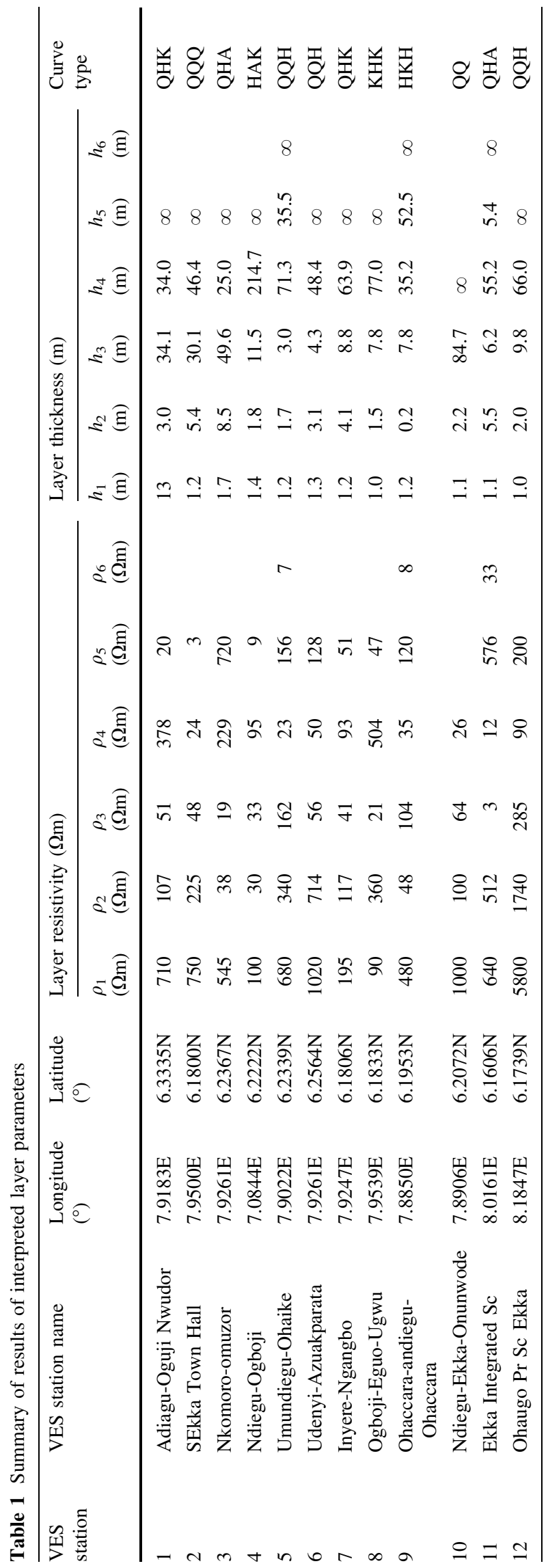

contamination from leachate. Areas that are moderate are less vulnerable, while areas with good protective capacity are not vulnerable to contamination from leachate infiltration. The average value of longitudinal conductance shows that the study area has good protective capacity. The weak protective capacity zone is associated with arenaceous material content compared to the areas with moderate and good protective capacity which the underlain aquifers are protected by the overlying argillaceous minerals.

The transverse resistance $(T)$ of the study area varies from 662.4 to $38,808 \Omega \mathrm{m}^{2}$ with an average value of $4375.85 \Omega \mathrm{m}^{2}$. The distribution of the aquifer transverse resistance is shown in Fig. 6. Maximum transverse resistance is observed in the western part of the area and part of the southeastern area. This indicates that the western part of the area has high thickness as can be seen from the isopach map, and it can be assumed that these areas may likely have high transmissivity and high yield of aquifer units.

The aquifer hydraulic conductivity $(K)$ with an average value of $12.83 \mathrm{~m} /$ day ranges from 1.1645 to $38.0491 \mathrm{~m} /$ day. The high range of hydraulic conductivity of aquifers is due to the heterogeneity of the aquifer sand repository, a condition responsible for wide range in hydraulic conductivity (George et al. 2015). Hydraulic conductivity is a measure of the ease with which a fluid will pass through a medium (Heigold et al. 1979). The distribution of hydraulic conductivity is shown in Fig. 7. It revealed that the greater part of the study area has low hydraulic conductivity values, indicating that groundwater flow in the area is not simple but complex because of the geologic controls of the confined aquifers.

The transmissivity contour map is shown in Fig. 8. The transmissivity $\left(T_{r}\right)$ value range from 89.66 to $2100.31 \mathrm{~m}^{2} /$ day (Table 2 ). Transmissivity values increase at the extremes of the study area, leaving the middle part with low values $\leq 600 \mathrm{~m}^{2} /$ day. Areas with high transmissivity values can be identified as areas of high waterbearing potential, and aquifer materials are highly permeable to fluid movement. The average transmissivity value of $789.83 \mathrm{~m}^{2} /$ day indicates that the area has moderate-tohigh aquifer potential.

The reflection coefficient $(\mathrm{Rc})$ and the fracture contrast $(\mathrm{Fc})$ are represented in contour maps (Figs. 9 and 10). Though the highest value is found at the $N-S$ part of the study area, reflection coefficient (Rc) is observed to be high at the western part of the study area. The values range from -0.7514 to 0.9200 with an average value of 0.0310 . The fracture contrast ranges from 0.1420 to 40.0424 with the average value of 3.337 . The highest value of the fracture contrast is obtainable at the southeastern part of the study area. Lower values of fracture contrast $(\mathrm{Fc})$ are 
Table 2 Summary of aquifer electrical and hydraulic parameters

\begin{tabular}{|c|c|c|c|c|c|c|c|c|}
\hline VES & $\rho_{b}(\Omega \mathrm{m})$ & $h(\mathrm{~m})$ & $S$ (mhom) & $T\left(\Omega \mathrm{m}^{2}\right)$ & $K$ (m/day) & $T_{r}\left(\mathrm{~m}^{2} /\right.$ day $)$ & $\mathrm{Rc}$ & $\mathrm{Fc}$ \\
\hline Adiagu-Oguji Nwudor & 51 & 34.1 & 0.6686 & 1739.1 & 9.8665 & 336.45 & -0.3544 & 0.4766 \\
\hline Ekk Town Hall Azugwu & 24 & 46.1 & 1.9208 & 1106.4 & 19.9313 & 918.83 & -0.3333 & 0.5000 \\
\hline Nkomoro-Omuzor Ogbo Ojiovu & 19 & 49.6 & 2.6105 & 942.4 & 24.7843 & 1229.30 & -0.3333 & 0.5000 \\
\hline Ndiegu-Ogboji-Ukwu Akpara & 95 & 214.7 & 2.2600 & $20,396.5$ & 5.5228 & 1185.74 & 0.4844 & 2.8788 \\
\hline Umundiegu-Ohaike & 23 & 71.3 & 3.1000 & 1639.9 & 20.7385 & 1478.65 & -0.7514 & 0.1420 \\
\hline Udenyi-Azuakparata & 50 & 48.4 & 0.9680 & 2420.0 & 10.0505 & 486.44 & -0.0566 & 0.8923 \\
\hline Inyere-Ngangbo Nwakpa Umobi & 93 & 63.9 & 0.6881 & 5942.7 & 5.6335 & 359.98 & 0.3881 & 2.2683 \\
\hline Ogboji-Eguo-Ugwu & 504 & 77.0 & 0.1528 & $38,808.0$ & 1.1645 & 89.66 & 0.9200 & 24.0000 \\
\hline Ohaccara-Ndiegu-Ohaccara & 120 & 52.5 & 0.4375 & 6300.0 & 4.4415 & 233.17 & 0.5484 & 3.4286 \\
\hline Ndiegu-Ekka-Onunwode Ndiegu & 64 & 84.7 & 1.3234 & 5420.8 & 7.9832 & 676.18 & -0.2195 & 0.6400 \\
\hline Ekka Integrated Pri. Sch Ekka & 12 & 55.2 & 4.6000 & 662.4 & 38.0491 & 2100.31 & 0.6000 & 4.0000 \\
\hline Ohaugo Pri Sch Ekka & 90 & 66.0 & 0.7333 & 5940.0 & 5.8085 & 383.35 & -0.5200 & 0.3158 \\
\hline Average & 95.42 & 71.95 & 1.6219 & 7609.85 & 12.83 & 789.83 & 0.0310 & 3.337 \\
\hline
\end{tabular}

Fig. 3 Contour map of the study area showing aquifer resistivity in ohmmeters

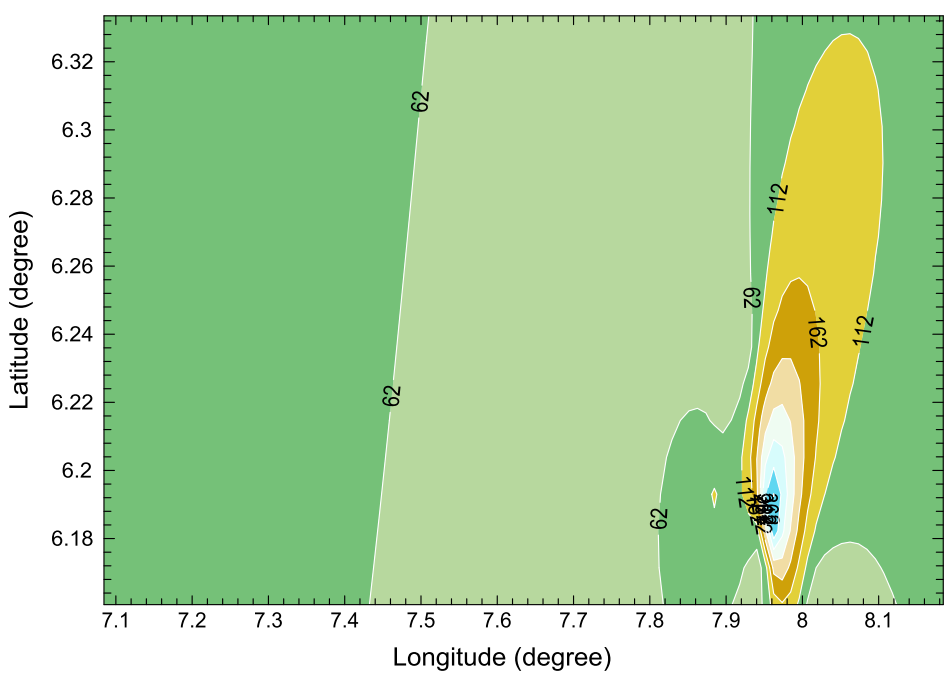

Resistivity (Wm)
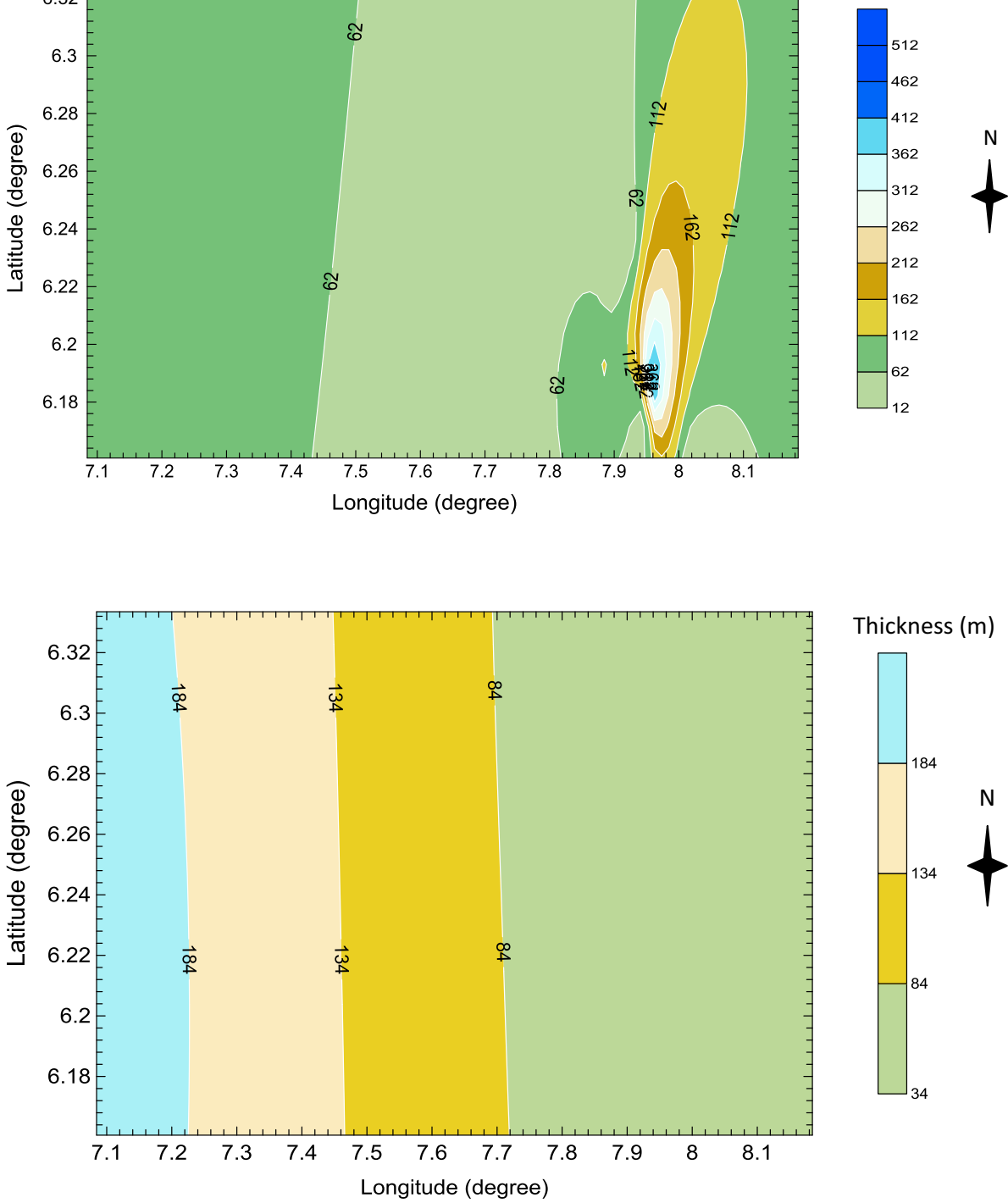

Thickness (m)

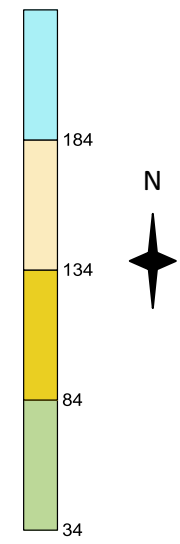

Fig. 4 Isopach contour map showing the variation of thickness in the study area 
Fig. 5 Contour map showing the distribution of longitudinal conductance in the study area

Fig. 6 Contour map showing the distribution of transverse resistance in the study area

Fig. 7 Map showing the distribution of aquifer hydraulic conductivity

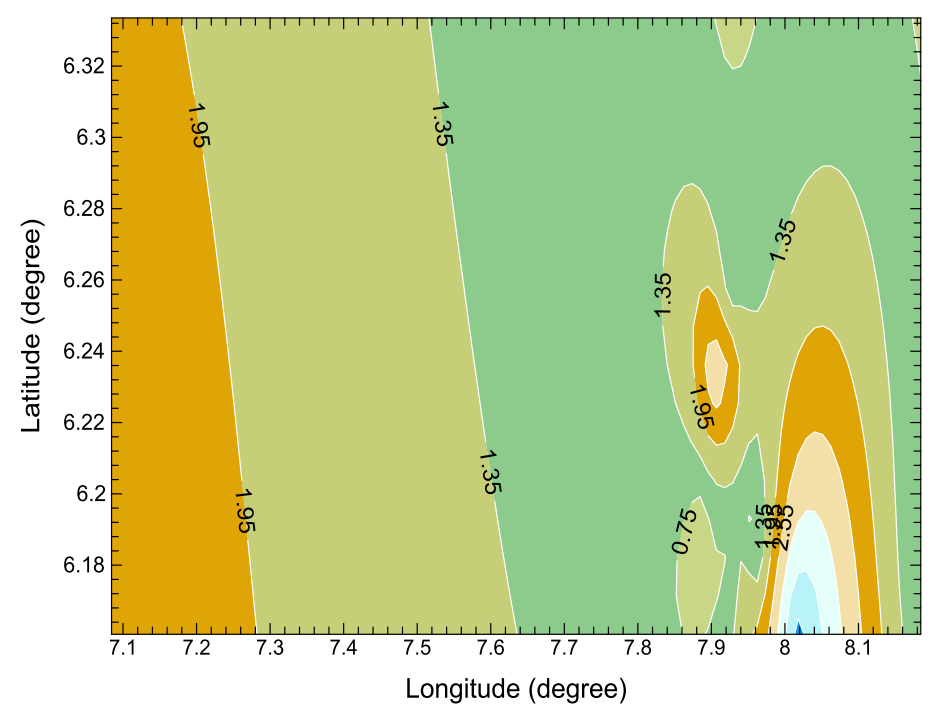

Longitudinal

conductance $\left(\mathrm{W}^{-1}\right)$
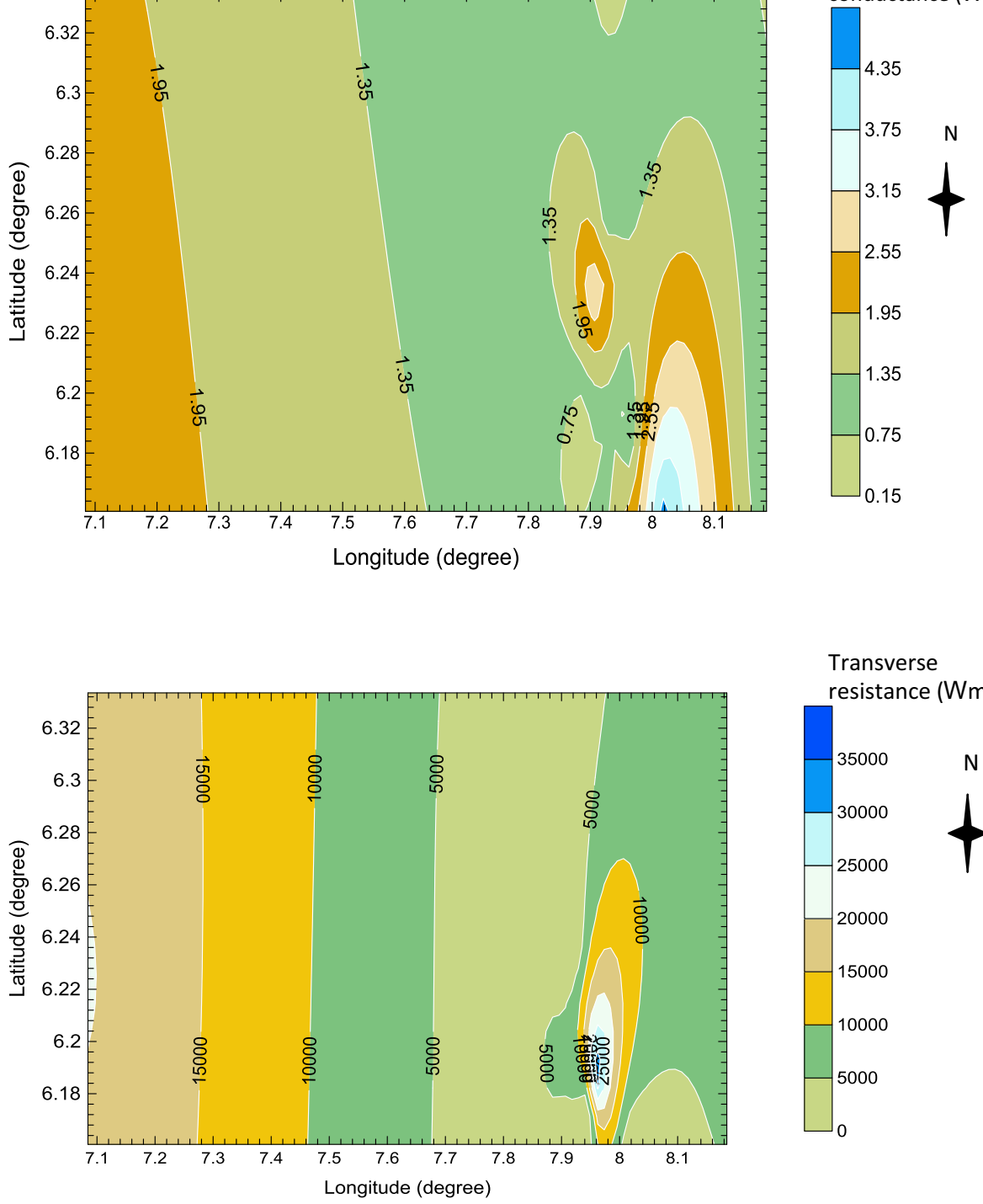

Transverse

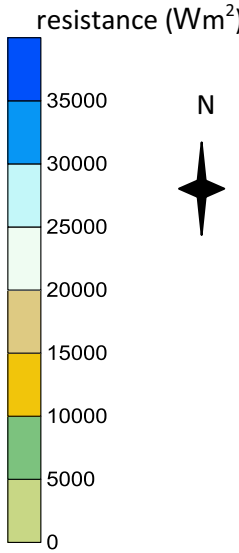

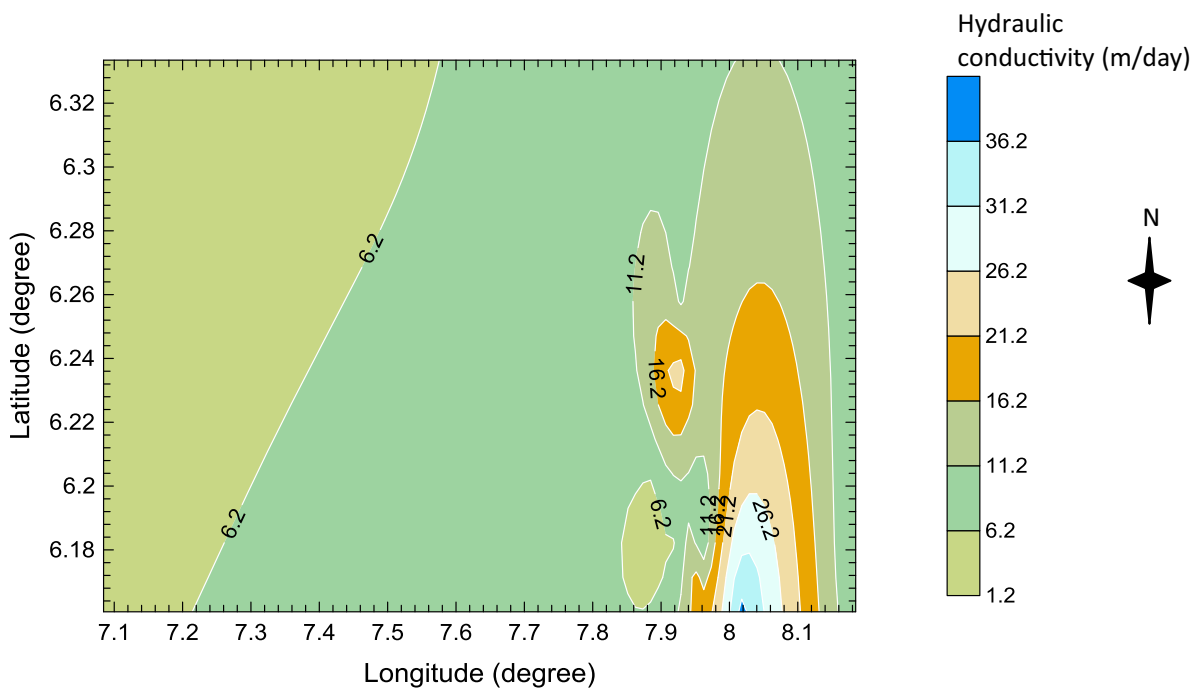


Fig. 8 Contour map showing the distribution of aquifer transmissivity in the study area

Fig. 9 Map showing the variation in reflection coefficient map

Fig. 10 Map showing the distribution of fracture contrast in the study area

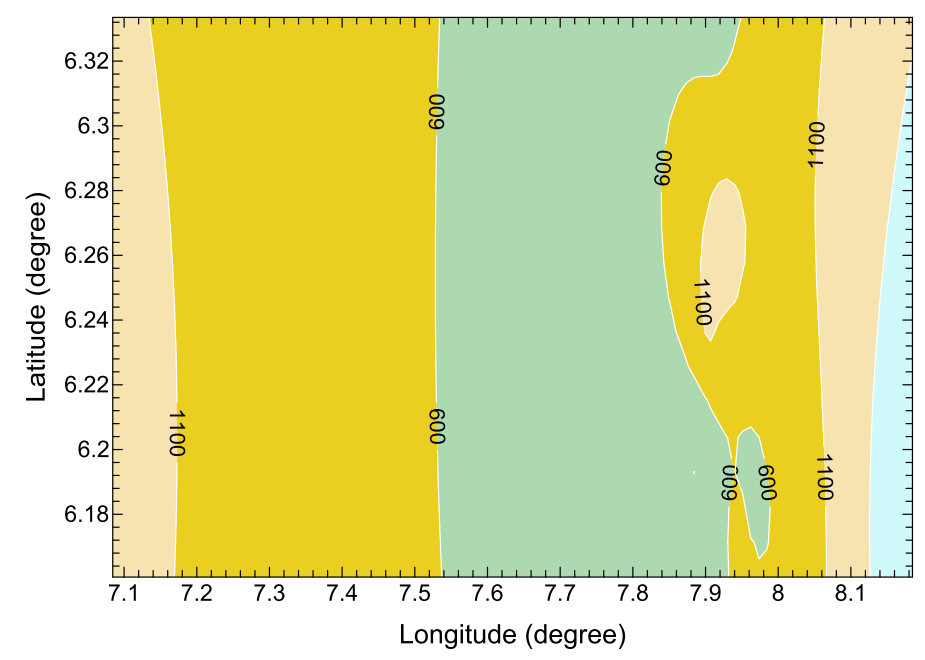

Transmissivity ( $\mathrm{m}^{2} /$ day)

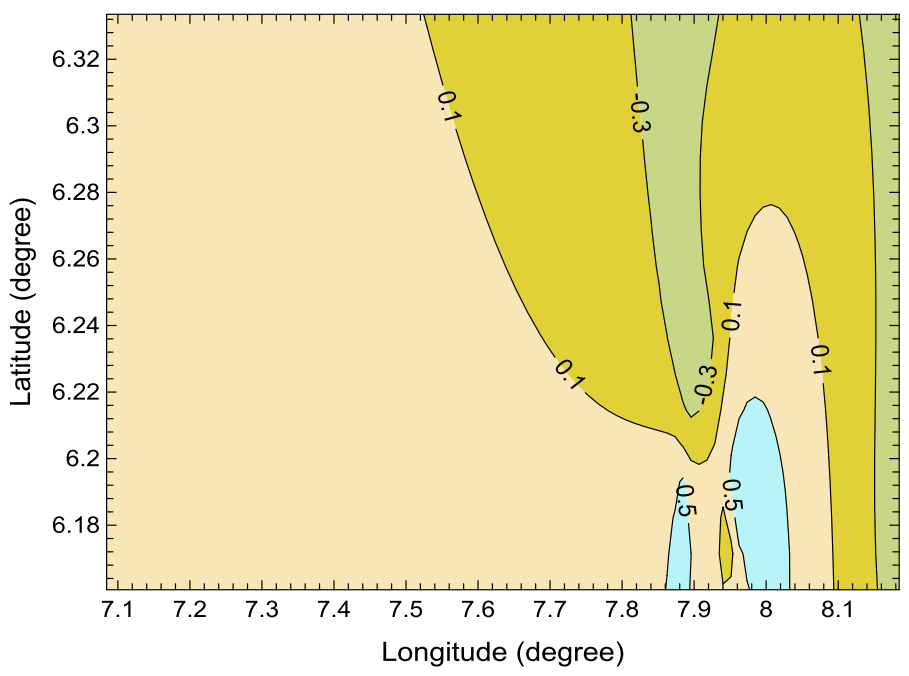

Reflection coefficient

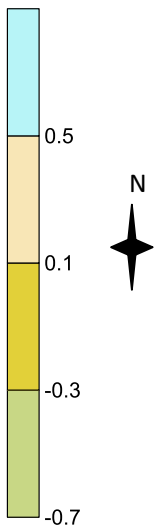

Fracture contrast

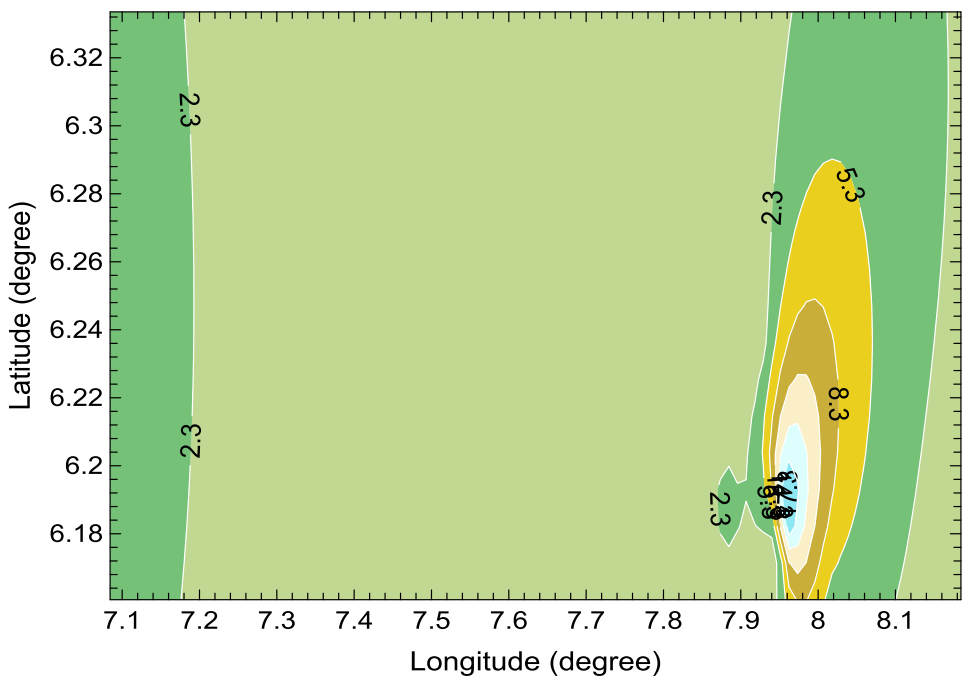


found in between the east and south part of the study area. It can be said that the reflection coefficient value $<0.9$ and resistivity contrast value $<19$ may indicate high-density water-filled fractures (Olayinka et al. 2000). Based on the spread of Rc and Fc in Figs. 9 and 10, respectively, the part of the mapped area in between the eastern and western parts of the study area is characterized with high-density water-filled fractures.

\section{Conclusion}

In this paper, the electrical resistivity sounding method was used to explore the study area and to evaluate the geoelectrohydraulic parameters. The results provide data on aquifer electrical and hydraulic parameters which included the longitudinal conductance, transverse resistance, hydraulic conductivity, transmissivity, reflection coefficient and fracture contrast. These parameters were used to generate different contour maps. The frequency of curve types indicates that the area is dominated by QQH curve type with 25 and $16.7 \%$ of QHK and QHA, respectively, while the rest have $8.3 \%$ each. The result revealed that areas with high transverse resistance values may give high aquifer yield; the study area has good aquifer protective capacity due to the argillaceous overlying clay materials and also moderate-to-high aquifer potential. The results also show that the shallow aquifers characterized with wide ranges of hydraulic conductivity caused by heterogeneous facies change in the area can be located in the fine-sand facies underlying the clayey formation.

Acknowledgments Authors are grateful to Dr. J. U. Chukudebelu, Department of Physics and Astronomy, University of Nigeria, Nsukka and Solomon Offiah, National Centre for Energy Research and Development, University of Nigeria, Nsukka, for their contributions and encouragement.

\section{References}

Agumanu AE (1989) The Abakaliki and the Ebonyi Formations: subdivisions of the Albian Asu River Group in the southern Benue Trough, Nigeria. J Afr Earth Sci 9(1):195-207

Akpan AE, George NJ, George AM (2009) Geophysical investigation of some prominent gully erosion sites in Calabar, southeastern Nigeria and its implications to hazard prevention. Disaster Adv 2(3):46-50

Al Sabahi E, Rahim SA, Wan Zahairi WY, Nozaily AI, Alshaebi F (2009) The characteristics of leachate and groundwater pollution at municipal solid waste landfill of Ibb City, Yemen. Am J Environ Sci 5(3):256-266
Bhattacharya PK, Patra HP (1968) Direct current geoelectric sounding: principles and interpretation. Elsevier Science Publishing Co., Inc., Amsterdam

Chakravarthi V, Shankar GBK, Muralidharan D, Harinarayana T, Sundararajan N (2007) An integrated geophysical approach for imaging subbasalt sedimentary basins: case study of Jam River Basin, India. Geophysics 72(6):141-147

Ekine AS, Osobonye O (1996) Surface geo-electric sounding for the determination of aquifer characteristics in parts of Bonny local government area of Rivers State. Niger J Phys 85:93-97

Evans UF, George NJ, Akpan AE, Obot IB, Ikot AN (2010) A study of superficial sediments and aquifers in parts of Uyo local government area, Akwa Ibom State, Southern Nigeria, using electrical sounding method. Eur J Chem 7(3):1018-1022

Ezeh CC, Ugwu GZ (2010) Geoelectrical Sounding for Estimating Groundwater Potential in Nsukka L.G.A, Enugu State, Nigeria. Int J Phys Sci 5(5):415-420

George NJ, Akpan AE, Obot IB (2010) Resistivity study of shallow aquifer in parts of southern Ukanafun Local government area, Akwa Ibom State. Eur J Chem 7(3):693

George N, Obianwu V, Udofia K (2011) Estimation of aquifer hydraulic parameters via complimenting surficial geophysical measurement by laboratory measurements on the aquifer core samples. Int Rev Phys 5(2):88-96

George NJ, Emah JB, Ekong UN (2015) Geohydrodynamic properties of hydrogeological units in parts of Niger Delta, southern Nigeria. J Afr Earth Sci 105:55-63

Heigold PC, Gilkeson RH, Cartwright K, Reed PC (1979) Aquifer transmissivity from surficial electrical methods. Gr Water 17(4):338-345

Henriet JP (1976) Direct application of Dar Zarrouk parameters in groundwater survey. Geophys Prospect 24:344-353

Ibuot JC, Akpabio GT, George NJ (2013) A survey of repository of groundwater potential and distribution using geoelectrical resistivity method in Itu L.G.A., Akwa Ibom State, Southern Nigeria. Central Eur J Geosci 5(4):538-547

Maillet R (1947) The fundamental equations of electrical prospecting. Geophysics 12:529-556

McDonald AM, Davies J, Dochartagh BEO (2002) Simple methods for assessing groundwater resources in low permeability areas of Africa. In: British geological survey commissioned report, CR/ $01 / 168 \mathrm{~N}$

Niwas S, Singhal DC (1981) Estimation of aquifer transmissivity from Dar Zarrouk parameters in porous media. Hydrology 50:393-399

Okoronkwo IL (2003) Guinea worm infestation: a case of Ezzagu community in Ebonyi State. West African Journal of Nursing, University of Nigeria Nsukka Virtual Library

Olawuyi AK, Abolarin SB (2013) Evaluation of vertical electrical sounding method for groundwater development in basement complex terrain of west-central Nigeria. Niger J Technol Dev 10(2):22-28

Olayinka AI, Obere FO, David LM (2000) Estimation of longitudinal resistivity from Schlumberger sounding curves. J Min Geol 36(2):225-242

Orellana E, Mooney H (1966) Master tables and curves for VES over layered structures. Interciencia, Madrid

Reyment RA (1965) Aspect of geology of Nigeria. University of Ibadan Press, Ibadan

Singh KP (2005) Nonlinear estimation of aquifer parameters from surficial resistivity Measurements. Hydrol Earth Syst Sci Dis 2:917-993 
Singh P (2007) Engineering and general geology for B.E. (Civil Mining, Metallurgy Engineering), B.Sc. and A.M.I.E courses. S.K. Katara and Sons, Delhi
Zohdy AAR, Eaton GP, Mabey DR (1974) Application of surface geophysics to groundwater investigations. United State Geophysical Survey, Washington 